\title{
Economic and Environmental Innovation Management of Plastic Waste
}

\author{
Ildikó-Csilla TAKÁCS \\ The Bucharest University of Economic Studies, Bucharest, Romania \\ csillatakacs12@gmail.com
}

Received date: 21 February 2019; Accepted date: 25 April 2019; Published date: 14 June 2019

Academic Editor: Gheorghe Durac

Copyright (C) 2019. Ildikó-Csilla TAKÁCS. Distributed under Creative Commons CC-BY 4.0

\begin{abstract}
The prominence of economic and environmental innovation management regarding plastic waste is transforming the revolutionary advancement of business excellence, therefore innovation has a primary position and is directly interrelated with the international organizations' objectives. Today, businesses face various transformation challenges since innovation management is deeply embedded in the new dynamics of global economic expansion and competition. In the forthcoming, enterprises have to be able to design incorporated innovative methods that are flexible and stimulate a new narrative of progress.

The objective of this paper is to emphasise the significance of the environmental innovation and economic management as principal sustainable business structures in order to support the hypothesis that one of the biggest problems with plastics as waste is that its reutilization or decontamination has not been solved yet. Thus, governance values have a huge impact on the organizational fulfilment in the innovation advancement, such as to protect the resources and the environment, seeking new ways of technical feasibility and economic viability by distributing economic benefits. All the scientific data are applied in a case study to propose a model of analysing and determining the need for innovative environmental strategies. The methodology used encompasses empirical research based on qualitative methods, outlining the decisive innovative factors towards more effective routines and transformation ascendency. The research results show a new invention and particular aspects of a business model when planning environmental innovation and highlight the importance of waste processing and destruction tool that leads to the growth of competitive, sustainable and innovative strategies.
\end{abstract}

Keywords: innovation management, environmental strategy, plastic waste, economic benefits

Cite this Article as: Ildikó-Csilla TAKÁCS (2019)," Economic and Environmental Innovation Management of Plastic Waste", Journal of Innovation \& Business Best Practice, Vol. 2019 (2019), Article ID 257377, DOI: $10.5171 / 2019.257377$ 


\section{Introduction}

Nowadays, one of the most serious global problems concerns the protection of creation. There are serious consequences of climate change, environmental pollution, social differences, global warming and the decline in biological diversity is aggravating the ecological equilibrium, threatening the environment.

It is no coincidence that Pope Francis has devoted his full first encyclical to this topic, the 'Laudato si', published in 2015. In the encyclical, there is a significant part of the waste problem, and in particular, plastic waste has the most important role and contribution. Over the last two decades, plastic production in the world has jumped hundreds of times, but waste management has not developed as it should have been.

The plastic problem can be related to almost all environmental problems. It has an impact on living organisms, including not a negligible fact on the people, on the ground, on the water and on the air. The first problem can be perceived at the time of its manufacture. Plastic can be manufactured easily, cheaply and in large quantities, resulting in a huge amount of production. However, the production of plastic is environmentally polluting, the production, transport and subsequent polymerization of raw materials and the delivery of finished products all cause significant environmental pollution, e.g. air and water pollution. Since they are manufactured in very large quantities, they will be used in significant extents, but due to their poor quality or function, they will be put into the garbage after usage.

As Pope Francis states "The earth, our home, is beginning to look more and more like an immense pile of filth. In many parts of the planet, the elderly lament that once beautiful landscapes are now covered with rubbish." (Laudato si \#21)
Subsequently, from the immense plastic garbage, only a very small amount will be taken to the garbage heap, the rest is blown by the wind, buried in the ground, carried by the water getting a large part of them into the ocean, forming huge plastic islands with which we cannot do anything. According to the latest environmental researches, if we do not find a solution for plastic waste by the middle of this century, there will be more plastic in the oceans than fish. Islands of garbage swim in the oceans, the albatrosses are destroyed by plastic waste in their breasts, and unfortunately, we are unable to cope with the mixed plastic waste, even though there is great potential in the problem.

After many years of work and hindrance, an enthusiastic Transylvanian team has finally gained confidence in a Hungarian invention; accordingly, we have progressed closer to recycling waste by creating jobs, mobilizing money, work and relationships. Therefore, our established company is ruled by awareness, organizing power, community ownership system of church communities and also committed engineering expertise, since we feel responsible to future generations for the viability of our land.

Our company the Székely Environmental Protection and Renewable Energetics Zrt. (co.ltd.) was founded in 2016 by two Szeklerland Enterprises: The Transylvanian Development Guarantee Fund, (Aqua Millennaris Ltd.) and the Entreprises of Csík basin's common land (Uniunea Composesoratelor), as well as two private individuals Msgr. Dr. József Darvas-Kozma, a papal chaplain, parish priest, president of the Economic Council of the Archbishop of Gyulafehérvár and Zsolt Fogarasi, the new inventor and the leader of the development engineer team.

The Székely Land Societies and Individuals also established a company registered and based in Hungary (Bicske, Kossuth L. 61 /A) because the support and 
administrative conditions in the home country are superior to those in Romania, especially in the case of minority enterprises. Based on the decision of the owners, by changing the temporary company structure, our company will serve a considerable degree of community interest, thus promoting the development of Szeklerland.

Since 2017, our Company has been engaged in research and development in the field of thermo-catalytic decomposition technology and other technologies with significant environmental performance and has also started planning its own production capacity. At the moment, it is developing a patent application under its own ownership involving the University of Miskolc Chemical Engineering and Technical Informatics Institute.

The Hungarian registered parent company is planning to build its first sample project in Csíkszereda, Székelyland, currently in the Romanian administrative area, involving the Hungarian State Capital Fund, which can achieve significant results in the environmental assessment of both countries.

Our entrepreneurship was created in the spirit of the papal Encyclical "Laudato si" and we wish to continue to operate it in the future. It is important for us to protect the sustainability, the resources as well as our environment, thus we seek new ways of technical practicality and economic feasibility by sharing the economic profits through the ownership system and participating in the educational, health and cultural system of our society.

\section{Theoretical considerations on the innovation of economic and environmental waste of plastics}

According to Greenberg et al. (2017), at present, there is a threatening industrial revolution, the consequences of which we have not thought through because of the immense consumer demand of mankind. With the spread of electric transport and with the increase of renewable energy sources, the demand will decline after 2030 in the fossil and mainly petroleum-based energy sources. Thus, as Andrews (2017) states, oil companies have already been investing in massive capacities to shift the extracted oil to produce plastic raw materials and plastics. As a result, the production of plastics will be multiplied over the next decade.

"We may well be leaving to coming generations debris, desolation and filth. The pace of consumption, waste and environmental change has so stretched the planet's capacity that our contemporary lifestyle, unsustainable as it is, can only precipitate catastrophes, such as those which even now periodically occur in different areas of the world." (Laudato si \#161)

Pope Francis mentions in his encyclical several times that everything is related to all, for example, plastic contamination with deprivation and social differences. The rich, who have caused utmost of the pollution, can defend much easily themselves against its harmful effects, can buy more expensive fish, can bring it from far, and can afford expensive medical treatments. While those members of the poorer countries who suffer furthermost of the adverse effects, cannot afford high-quality medical care, henceforth when the fish are drowned in plastic bags, they are starving.

Wrigley and Straker (2016) advocated several methods that can be employed and selected by each corporation according to their profiles and enterprises. The developed countries that are mainly responsible for the pollution must be obliged for taking care of the pollution that they have caused. Those countries are obliged even from their Humanitarian funds for the recycling process, including environment protection, local job creation and energy independency.

Decomposing plastic has an incredibly harmful effect on wildlife. The pieces of plastic material that is still visible are eaten by living creatures that will destroy them because they cannot digest it. The disintegration of the plastic falls apart into 
pieces not visible to the eyes, which are swallowed by the living creatures on the food chain, and the creatures on the higher levels of the food chain eat the living entities of the underlying level. These tiny particles contract into the water and grow into the organisms, naturally, in the human body as well. In addition, drinking water nowadays is contaminated, full of chemicals that are poisonous, disrupt the homeostasis, our hormone system, which has an effect for example on our reproductive ability.

Though the plastic goes into the garbage collector, it is not the perfect solution, as it is preserved there, stored until it is decomposed or incinerated. Provided it is burned, the mass of harmful substances transfers into the air. On the assumption that it is stored, it contracts a lot of energy to be kept out of the environment so that the resulting harmful substances not to move out of the container that is rarely accomplished, without mentioning how much space it is necessary for this process.

Engineers of the Székely Environmental Protection and Renewable Energetics Zrt. recognizing the problem, found a solution and in this way, the new innovative idea of recycling was born. Plastics that can be recycled in their materials are only $8 \%$ of all waste besides $10 \%$ of them are only PET.

\section{Empirical considerations on the innovation of economic and environmental waste of plastics}

Hungarian researchers and designing engineers have developed a closed-loop system that can be built in a $40 \mathrm{ft}$ container frame and can be transported either on a train, or on a truck to the desired location, such as hospital, or waste management site. Naturally, it can also be equipped on a sea-ship or industrial waste collection ship that can process the generated or collected waste continuously so that it will not harm the environment and, in addition, produces a high proportion of recyclable end products (recycle energy carriers). These products can also be used in Power Engineering and plastics production.
This technology, unlike the other similarly developed procedures, has the advantage of being non-stationary, serving not only a multi-interest but also giving them a strong competitive edge and assures advantages to communities, for example, in district heating or in electricity generation, or in an industrial environment switched to a waste selection technology.

Transylvanian communities can supply the technology line with raw materials, workforce, operation and thus direct support through the energy system by significantly reducing the district heating or electricity costs. This technology, similar to the Henderson Project, is also able to operate on an island with smaller capacity, but can also function independently, process the waste there and provide energy for the people proximate.

The aim of our investment is to build a factory and to set up and install the production line that manufactures this waste processing and destruction tool. Furthermore, taking into account the composition of the waste, it is capable of producing an improved version of standard plastics waste for the processing of extreme waste of e-waste, as well as the manufacture of other inventive devices that improve its efficiency and operating time.

In order to further develop the product and to start up the capacity of the production, besides the support of the Hungarian state, we also expect that a significant part of the money from production and operation will be reinvested in development, community support, a new value-based community based on faith, morality and education.

Overall, in a previous study, Takacs (2018) defines that a prosperous innovation management should invest in strategy developing methods, and support for diverse cultures so as to join people with different perspectives to share production and new advances, combining entrepreneurial mind-sets with recognized and functioning expertise.

\section{Research Objectives and Methodology}


The objective of this research study is to identify the principles that affect the environmental innovation strategies, as well as to do research on the degree of innovation management in Székely Environmental Protection and Renewable Energetics Zrt. Transylvanian corporation with the help of the Miskolc university. The author has focused on the topmost innovative Hungarian invention as a key player in transforming strategy into practical accomplishment and its impact on the owner of business superiority to be applied, according to Berger et al. (2009).

This exploration shows that the Székely Environmental Protection and Renewable Energetics Zrt is especially proficient at continually responding to environmental innovation and encouraging practical risktaking and supporting worthy attempts, as well as organising the plastic waste source of quality and productivity gain. In terms of research approach, we have used the rational model as our contextual framework to clarify what standards and practices ought to be incorporated into the innovative company and to emphasise the role of the invention to manage the innovative principles of the administration.

The methodology used involves state-ofthe-art technologies developed by design engineers, managers and experts from the Hungarian corporation and renowned universities in order to gather scientific data that was evaluated and applied in a case study so as to propose a method of analysing innovative considerations.

Principally, the selected production control systems comply with Industry 4.0 recommendations, so we desire to operate an automated warehouse to store flat disks (STOPA) and its connected equipment form a unified and flexible production system. This ensures the joint storage of raw materials and semi-finished products, as well as the complete automation of all operations until welding.

The associated Production Management System (FAB) includes the entire supply chain process from raw material procurement to the delivery of finished products to end users and includes various product-related services, such as service, waste management, and recycling. Furthermore, FAB implements M2M technology, a data flow that takes place between machines without human intervention. Machine-to-machine communication is not just a simple flow of data, but also independent decision-making and intervention.

FAB is a computer system for monitoring production processes, which means realtime monitoring of the company's manufacturing processes. The system provides information on the status of production orders, material consumption during production, breakdowns, production losses, capacity utilization of production equipment, scheduled maintenance periods, and operating hours. One of its most valuable services is to organize data gathered from parallel production activities, provides aggregate information on production executives and their managers, supporting and accelerating the necessary decisions and the implementation of measures. 


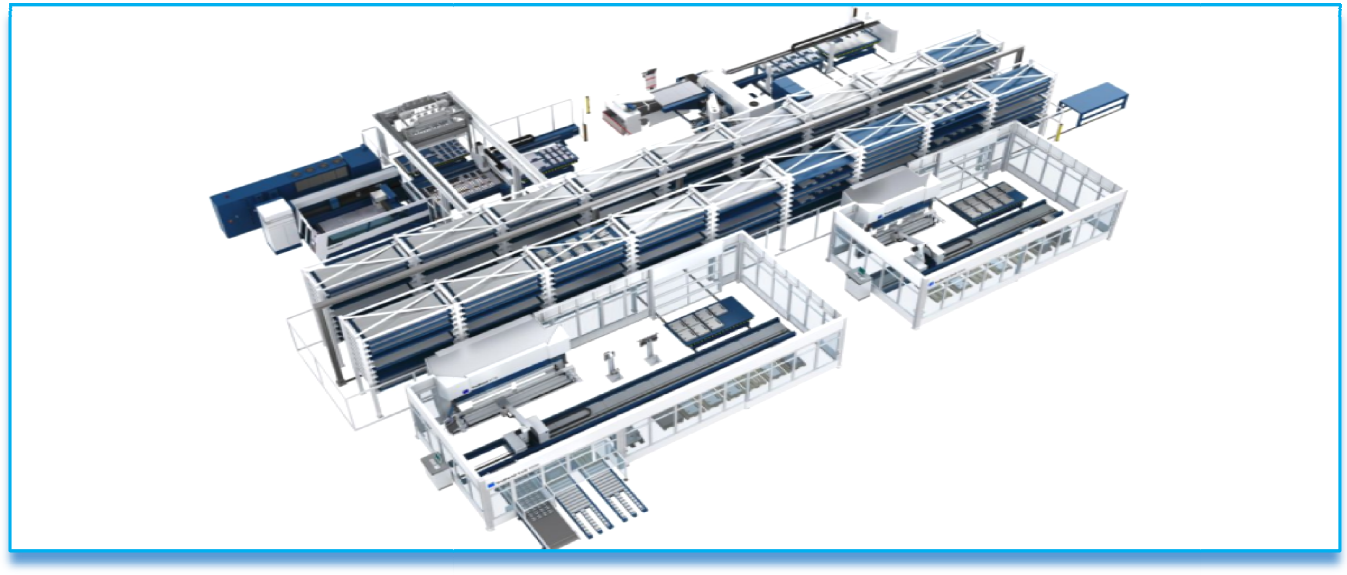

Fig.1: The Associated Production Management System, Source: The planned manufacturing environment is the TRUMPF Industry 4.0 manufacturing technology and warehouse system.

Ultimately, the neutralization of hazardous waste generated in hospitals is a serious problem and entails considerable costs. The basically plastic waste recycling technology that we have developed is well suited for offsetting hazardous waste generated in hospitals. The technology delivers waste to the cutter with a screwdriver, leaving WTS technology in the hopper. The technology is also able to receive medical plastic waste, thus the operating temperature of the equipment should be adjusted to a temperature between 600 and $650{ }^{\circ} \mathrm{C}$ for the thermocatalytic thermal decomposition processing, which can meet the requirements for deactivating hazardous waste.

Moreover, closed, emission-free technology, depending on the composition of the input, produces gas-type hydrocarbons at this temperature. By utilizing gas scrubbing engines, we can produce a significant amount of heat and electricity, which can be utilized in the supply of hot water and heating systems. The system produces storable energy sources (gas, oil and coke), so the electricity and heat supply can be adjusted to the needs in a controllable way.

Additionally, long-lived storage sites have high energy and raw material opportunity, but their re-usage requires special technology in a closed and ventilated system. In these storages, the emitted Methane makes the greenhouse effect 17 times more than the $\mathrm{CO} 2$ and cannot be recycled in nature. Therefore, we are working on this development in cooperation with $3 B$ Hungária Ltd.

Summarizing a number of perspectives, a significant part of the bill for the urban district heating is the cost of gas or other energy, which is $78-80 \%$ and only $20-25 \%$ is part of maintaining the system. The system we worked out provides largely independency of energy, it is decentralized, and therefore the loss of heat transport can be minimized. Due to its special effects, the reduction of the district heating bill is also possible. This significantly increases the security of housing estates strategy.

Thus, the system we recommend can be put into the system after the plastic 
(material non-reversible) waste, whether it is a car bumper, a milk bottle, a monitor casing or just rubbish trash, where it is converted to hydrocarbons and 5-15\% in a non-flammable environment with heat breakdown high-carbon metallurgical slagforming material.

\section{Research Results and Proposed Methods}

The main product that we have designed to manufacture is a multi-patented mixed plastic waste recycling technology, the EF System PR500, nevertheless, we will also develop and manufacture additional environmental and renewable energy products.

The EF System PR500 is a 1-reactor technology, which is capable of converting $500 \mathrm{~kg}$ per hour, yearly 4000 tons of mixed, non-recyclable plastic waste into closed systems, in an adjustable way with the currently most possible emission and with a thermochemical process, condensation, separation and post-treatment from which $60-70 \%$ fractionated crack oil $(\sim 400-450$ litres/h), $100 \mathrm{~m} 3$ combustible, (methane, ethane, propane, butane) gas and $5-10 \%$ as a high-carbon solid fraction in metallurgy. The technology is modular, mobile, the space required for the 40-foot container + server area is approx. $200 \mathrm{~m} 2$, so by their parallelization, any processing or electrical capacity can be created locally in a decentralized manner.

Successively, fuels can be rectified like petrol and diesel fuel, which can be used for specially prepared but highenvironmental series engines, and with the torque produced here, we operate a very high-efficiency cavitation device, to which the residual heat of the engine is added. According to TÜV Reinland certification (Technical Inspection Association), the efficiency of the cavitation system is $470 \%$. This fuel can also be raw material for new plastic production.

Table 1: Sales and Costs of EF Equipment Operation, Source: Author

\begin{tabular}{|c|c|c|c|}
\hline $\begin{array}{l}\text { Technological unit for oil and } \\
\text { gas production }\end{array}$ & $\begin{array}{l}2019-2020 \\
\text { EF System } 300\end{array}$ & $\begin{array}{l}\text { From } 2020 \\
2 \text { pc. of EF } \\
\text { System } 300\end{array}$ & $\begin{array}{l}\text { From } 2020 \\
1 \text { pc. of EF System } \\
3001 \text { pc. EF System } \\
1000\end{array}$ \\
\hline EF System 300 Technology - pc. & 1 & 2 & 4 \\
\hline Price of technology units - EUR & 2.400 .000 & 4.800 .000 & 7.900 .000 \\
\hline Operation hours & 8.200 & 8.200 & 8.200 \\
\hline Processes quantity per hour - kg & 300 & 600 & 1.300 \\
\hline Plastic quantity - tons & 2.400 & 4.800 & 10.600 \\
\hline The resulting crack oil $70 \%$ - kg & 1.680 .000 & 3.360 .000 & 7.462 .000 \\
\hline Gas generated $25 \%-\mathrm{m} 3$ & 600.000 & 1.200 .000 & 2.665 .000 \\
\hline Coke generated $5 \%$ - kg & 120.000 & 240.000 & 533.000 \\
\hline $\begin{array}{l}\text { Revenue - Average revenue from } \\
\text { the sales of cracked oil price EUR } \\
0.5 \text { / kg - EUR }\end{array}$ & 840.000 & 1.680 .000 & 3.731 .000 \\
\hline $\begin{array}{l}\text { Sales price of the produced coke } \\
200 \text { EUR/tons - EUR }\end{array}$ & 24.000 & 48.000 & 106.600 \\
\hline $\begin{array}{l}\text { Savings fee of waste laying } \\
53 \text { EUR/tons - EUR }\end{array}$ & 127.200 & 254.400 & 564.980 \\
\hline $\begin{array}{l}\text { Average Direct Cost } \\
\text { - Wage for } 12 \text { - } 17 \text { people - EUR } \\
\text { - operation of technology } \\
\text { - maintenance WTS - EUR }\end{array}$ & $\begin{array}{c}156.000 \\
\text { own produced } \\
\text { gas } \\
46.000 \\
\end{array}$ & $\begin{array}{c}156.000 \\
\text { own produced } \\
\text { gas } \\
92.000\end{array}$ & $\begin{array}{c}218.400 \\
\text { own produced } \\
\text { gas } \\
184.000 \\
\end{array}$ \\
\hline Operating profit from sales of & 789.200 & 1.734 .400 & 4.000 .180 \\
\hline
\end{tabular}


products EUR

Using $500 \mathrm{~kg} / \mathrm{h}$ of waste, approximately $10 \mathrm{MW}$ of permanent heating power can be generated, but this demand for district heating can be scaled up to about 20$25 \mathrm{MW}$ peak power due to fluctuations. Attached is the qualification and results of the cavitation system. The heat demand of the 268MW peak in a middle-sized town like Debrecen (Hungary) can be made energy-independent by 16 systems in a decentralized manner, while the operation of the systems and the return on financing would allow a reduction of circa. 30-40\%.

Furthermore, district-heating units are planned to be installed in a 300- and 600$\mathrm{kW}$ units on the district heating ridge, decentralized to the needs, thus minimizing the transmission heat loss of up to $20 \%$. The controllability is continuous as the units themselves can be controlled and switched on from a central control room, hence the operation can be kept close to the ideal. Because fuel can be transported, large residential systems can be serviced alongside the large system, virtually connected to the district heating system. Due to the fact that the energy carrier is transportable, more other settlements can be applied.

Estimated heat output is constant at 3-4.5 MW, which can be tailored to the needs, so during the winter, the stored energy carrier also allows for increased energy demand for heating. If the mixed hazardous waste to be neutralized does not reach the $250 \mathrm{~kg}$ per hour, it can be supplemented from the waste collectors in the area or from companies producing industrial plastic waste.

Table 2: Revenue from the expected sale, Source: Author

\begin{tabular}{|c|c|c|c|c|}
\hline Cash Received & 2019 & 2020 & 2021 & 2022 \\
\hline \multicolumn{5}{|l|}{ Cash from Operation } \\
\hline Cash Sales & & 18000000,00 & 30000000,00 & 90000000,00 \\
\hline Cash from Receivables & 1500000,00 & 30000000,00 & 30000000,00 & 20000000,00 \\
\hline Subtotal Cash from Operation & 1500000,00 & 48000000,00 & 60000000,00 & 110000000,00 \\
\hline New investment received & 40000000,00 & 60000000,00 & 20000000,00 & 20000000,00 \\
\hline Subtotal Cash Received & 41500000,00 & 108000000,00 & 80000000,00 & 130000000,00 \\
\hline \multicolumn{5}{|l|}{ Expenditure } \\
\hline Expenditure of Operations & 5000000,00 & 12000000,00 & 12000000,00 & 12000000,00 \\
\hline Cash Balance & 36500000,00 & 96000000,00 & 68000000,00 & 118000000,00 \\
\hline
\end{tabular}

Conclusively, the budget is linked to additional $R \& D$ because the factory wants to produce its own Thermo-Hybrid Revolver engine and Cavitation heater for its own operation, and can also accept external orders for full utilization of the manufacturer's capacity. It will be the country's largest non-automotive 3D plate and hollow tube manufacturing plant, which initially has significant free capacity. Revenue from the expected sale will be reinvested in the full construction of the factory site, in the social conditions of the workers and in the development of the factory and its products.

\section{Conclusions}

Our goal is to build a 21st-century factory that with its products, work-centeredness, lifestyle, and education will be similar to 
the big factories of the 19th century like FORD, MICHELIN, or Hungarian GANZ.

Cost planning was based on cautious and careful surveys, cost estimates, price quotes, and price comparisons taking into account state-of-the-art high-tech, greenfield and green roof investment, industry 4.0 expectations, safety, health, and hygiene.

The investment creates jobs, so at the start of production, i.e. at the end of the investment period, the minimum number of employees will be 150 , while the total number of employees is expected to be more than 600 . The human policy strategy will definitely count for the highly qualified, middle-level and expert professionals that is expected to be the largest part of automated and robotic production. Its wage policy is in proportion to and close to the European average wage level so that it can bring back professionals to Hungary and Transylvania with international practice.

Overall, our generation is struggling with the most important fundamentals: the need for clean and drinking water and how to get rid of plastic waste in such a way that it can produce energy for the next generation. The investment is in all respects in line with the goals of a government-specific application for a plant for innovative equipment that addresses one of the greatest social and environmental problems of our time waste treatment, high and economical disposal and/or recycling, it also creates a significant number of jobs. Conversely, it is our generation's responsibility to leave a viable planet for the future generations and participating in the educational, health and cultural system of our society.

\section{References}

1. Andrews, E., (2017), "Is Tech disruption good for the economy?", Stanford Business. [Online], [Retrieved September 12, 2017], https://www.gsb.stanford.edu/insights/te ch-disruption-good-economy
2. Berger, R., Dutta, S., Raffel, T., Samuels, G. (2009) Innovating at the Top: How Global CEOs Drive Innovation for Growth and Profit, Palgrave Macmillan, New York.

3. Greenberg, E., Hirt, M. and Smit, S. (2017), 'The Global forces inspiring a new narrative of progress', McKinsey Quarterly.

4. Pope Francis, (2015), "Laudato Si" [Online], [Retrieved October 10, 2018], http://w2.vatican.va/content/dam/frances co/pdf/encyclicals/documents/papafrance sco_20150524_enciclica-laudato-si_en.pdf

$\begin{aligned} & \text { 5. Takács, I. Cs. (2018) } \\ & \text { Innovation 'Strategic } \\ & \text { Management } \\ & \text { Through }\end{aligned}$
Organizational Change', Journal of
Innovation \& Business Best Practice, Vol.
2018 (2018), Article ID 863719, IBIMA,
USA, pp. 1 - 10, ISSN 2166-0743, DOI:
10.5171/2018.863719,
http://ibimapublishing.com/articles/JIBBP
/2018/863719/

6. Takacs, I. Cs. (2017), 'Case Study on Strategic Innovation Management through Organizational Change' Proceedings of the $30^{\text {th }}$ International Business Information Management Association (IBIMA), ISBN 978-0-9860419-9-0, 8-9 November 2017, Vision 2020: Sustainable Economic development, Innovation Management, and Global Growth, Madrid, Spain, 4662-4672.

7. Wrigley, C and Straker, K. (2016), 'Designing innovative business models with a framework that promotes experimentation', Strategy \& Leadership, 44(1), 11-19. 